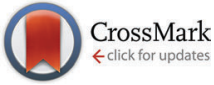

Cite this: J. Mater. Chem. C, 2016 4, 4927

Received 15th March 2016,

Accepted 20th April 2016

DOI: $10.1039 / c 6 t c 01098 a$

www.rsc.org/MaterialsC

\title{
Massive Ag migration through metal/ceramic nano-multilayers: an interplay between temperature, stress-relaxation and oxygen-enhanced mass transport $\dagger$
}

\author{
Mirco Chiodi, ${ }^{\star a}$ Claudia Cancellieri, ${ }^{a}$ Frank Moszner, ${ }^{a}$ Mariusz Andrzejczuk, ${ }^{b}$ \\ Jolanta Janczak-Rusch and Lars P. H. Jeurgens*a
}

\begin{abstract}
The phase stability and microstructural evolution of nano-multilayer (NML) coatings during thermal treatments have attracted increasing attention in several technological fields, such as plasmonics, optics and joining. In the present study, the microstructural evolution of $(\mathrm{Ag} / \mathrm{AIN})_{5 \mathrm{~nm} / 10 \mathrm{~nm}} \mathrm{NML}$ coating upon heating in air and under vacuum was investigated by a combinatorial approach using SEM, TEM, XPS and XRD (both in the laboratory and at the synchrotron facility). Fast heating of the $\mathrm{Ag} / \mathrm{AIN} N \mathrm{NL}$ in air up to $420{ }^{\circ} \mathrm{C}$ leads to an extensive migration of nano-confined $\mathrm{Ag}$ to the $\mathrm{NML}$ surface at temperatures as low as $200{ }^{\circ} \mathrm{C}$, much below the Ag bulk melting point. Remarkably, the migration of Ag towards the surface is negligible for a similar heat treatment under vacuum, as well as for a thick Ag layer (i.e. in the absence of a nano-confinement of Ag). Outward migration of $\mathrm{Ag}$ is driven by the reduction of internal interfaces (i.e. nanograin- and phaseboundaries) in combination with the relaxation of thermally induced compressive stresses. The enhanced mobility of $\mathrm{Ag}$ in an O-rich atmosphere is attributed to the reduction of the activation energies for vacancy formation in the confined Ag nanolayers, as induced by the chemical interaction of inwardly diffusing $O$ with Ag along Ag/AlN interfaces. The combined effects of nano-confinement, thermal stresses and an O-rich atmosphere in the Ag/AIN NML may be exploited for novel low-temperature joining applications.
\end{abstract}

\section{Introduction}

Nanoscale devices promise substantial technological advancements in numerous fields, such as in electronics, catalysis, optics, energy storage and medicine. ${ }^{1-4}$ Nowadays, several different approaches are routinely used to produce nanomaterials, including sol-gel techniques, supersonic cluster beam depositions, pyrolysis, milling processes, and chemical- and physical-vapor deposition (CVD/ PVD).$^{5-9}$ Over the past few decades, layer-by-layer assembly of thin films by PVD has been vastly exploited, because it enables low-cost fabrication of functional nanostructures with tunable properties on a wide range of substrate materials. ${ }^{10,11}$ Nano-multilayer (NML) configurations, in which alternating layers of different materials are stacked with a given periodicity, are among the most common

\footnotetext{
${ }^{a}$ Empa, Swiss Federal Laboratories for Materials Science and Technology, Laboratory for Joining Technologies and Corrosion, Überlandstrasse 129, 8600 Dübendorf, Switzerland. E-mail: mirco.chiodi@empa.ch, lars.jeurgens@empa.ch

${ }^{b}$ Warsaw University of Technology, Faculty of Materials Science and Engineering, Woloska 141, 02-507 Warsaw, Poland

$\dagger$ Electronic supplementary information (ESI) available: SEM of samples heated in UHV and/or without nano-confinement; XRD simulation; real-time XRD and stress evaluation details. See DOI: 10.1039/c6tc01098a
}

nano-architectures fabricated by PVD. The high density of heterointerfaces in such NMLs imposes dimensional and microstructural constraints to the mobility of atoms, defects, electrons, photons, phonons and plasmons, which results in unusual electronic, optical, magnetic and mechanical properties. ${ }^{12-15}$ Evidently, the functional properties of NML structures strongly depend on the bilayer periodicity, individual layer thicknesses and, in particular, on the (defect) structure of the internal interface. ${ }^{16}$ Hence, novel functional devices based on NML architectures can be designed by controlling size effects and by interface engineering.

Recently, metal/ceramic NMLs have attracted huge interest in various application areas, such as those related to plasmonic devices, ${ }^{17,18}$ nano-joining technologies ${ }^{19-21}$ and optical coatings. ${ }^{22}$ The applicability of these emerging NML-based technologies critically depends on the thermal, chemical and mechanical stability of the NML structure during fabrication, processing and subsequent operation, which may involve thermal treatments, exposure to reactive gases or liquids and/or thermo-mechanical loadings. For example, Siozios et al. reported one of the first studies on $\mathrm{Ag}$ diffusion through Ag/AlN multilayers by controlled laser annealing in air, which resulted in a homogeneous dispersion of $\mathrm{Ag}$ nanoparticles throughout the AlN layers. ${ }^{18,23}$ The size and distribution of the $\mathrm{Ag}$ nanoparticles were found to strongly depend on the 
microstructure of the as-deposited $\mathrm{Ag} / \mathrm{AlN}$ layers and hence on the deposition conditions. ${ }^{17}$ Moreover, it was observed that slower thermal annealing in air results in the outward diffusion and self-organization of Ag in small nanoparticles at the surface, whereas faster local heating by laser annealing induces local crystallization of the AlN matrix (as associated with an enhancement and a shift of the surface plasmon resonance). ${ }^{24}$ On the basis of these experimental findings, the effects of the deposition parameters and laser treatment (i.e. number of laser pulses, wavelength, fluence) on the microstructural evolution of $\mathrm{Ag} / \mathrm{AlN}$ NMLs were elucidated. ${ }^{25}$

Only very recently, $\mathrm{Ag} / \mathrm{AlN}, \mathrm{Cu} / \mathrm{AlN}$ and $\mathrm{Ag}-\mathrm{Cu} / \mathrm{AlN} \mathrm{NML}$ coatings have also been envisaged as low-temperature brazing nano-fillers for packaging and assembling miniaturized devices and heat-sensitive components at ever-reduced processing temperatures. ${ }^{20,21,26}$ Such NML brazing fillers are typically composed of alternating nanolayers (individual thickness $\leq 10 \mathrm{~nm}$ ) of a metal (or alloy) and a chemically-inert barrier (e.g. oxides, nitrides or refractory metals). Using NML coatings, the brazing temperature can be lowered by exploiting the effects of a size-dependent melting point depression of the confined metal and the intrinsically high atomic mobility along internal interfaces (e.g. incoherent phase interfaces and high-angle grain boundaries). ${ }^{27}$ Alternatively, nanoparticle pastes constituting a noble-metal (e.g. $\mathrm{Ag}$ or $\mathrm{Au})^{21}$ are considered as promising candidates for low-temperature joining applications. However, health and safety issues related to the handling of nano-particle pastes still limit their potential use on a large scale. With this regard, low-temperature joining using NML coatings could be a real technological breakthrough, provided that the directional migration (outflow) of the confined metal filler can be triggered and exploited for chemical bonding at low temperatures, forming a solid joint. ${ }^{19-21}$

Still, to the best of our knowledge, comprehensive investigations of the driving forces and underlying mechanisms which govern the phase stability and atomic mobility of confined metals in NMLs during heating have not been reported yet. The current work presents a comprehensive experimental investigation of the microstructural evolution of Ag/AlN NML coatings upon heating in air and under UHV by application of a combinatorial analytical approach using scanning electron microscopy (SEM), transmission electron microscopy (TEM), X-ray spectroscopy (XPS) and X-ray diffraction (XRD). The experimental findings indicate that both the processing atmosphere and the stress state play a fundamental role in determining the thermal evolution of the system. These combined effects could be exploited to activate and direct the migration of Ag to the NML surface, allowing chemical bonding at strikingly low temperatures. The underlying mechanisms for this low-temperature process are disclosed and discussed.

\section{Experimental}

\subsection{Sample preparation}

$\mathrm{Ag} / \mathrm{AlN}$ NMLs were deposited on $2^{\prime \prime}$ epi-polished $\alpha-\mathrm{Al}_{2} \mathrm{O}_{3}(1 \overline{1} 02)$ single-crystalline wafer substrates (i.e. sapphire- $\mathrm{R}$ wafers) by magnetron sputtering in a high vacuum chamber (base pressure $<$ $1 \times 10^{-8}$ mbar) from two confocally arranged unbalanced

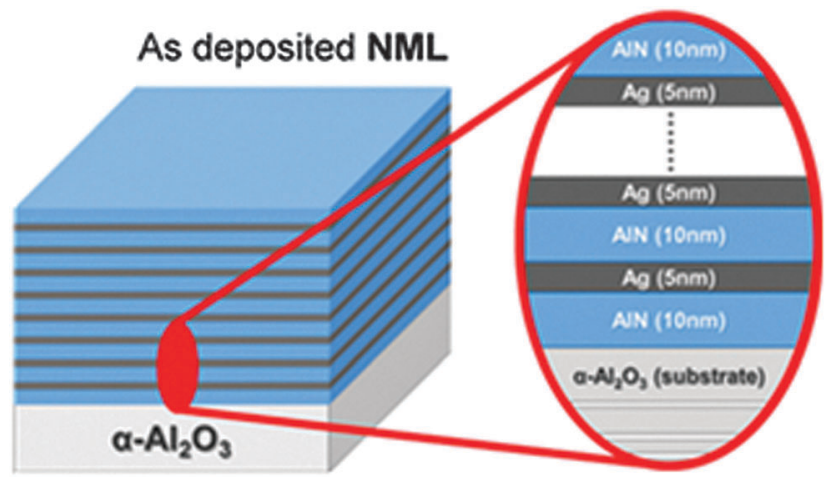

Scheme 1 Structure of the as-deposited (Ag/AIN) $5 \mathrm{~nm} / 10 \mathrm{~nm}$ NML coating.

magnetrons equipped with $2^{\prime \prime}$ targets of pure Ag (99.99\%) and $\mathrm{Al}$ (99.99\%). Before insertion in the deposition apparatus, the sapphire substrates were ultrasonically cleaned in acetone and isopropanol. Prior to deposition, possible surface contamination on the $\alpha-\mathrm{Al}_{2} \mathrm{O}_{3}(1 \overline{1} 02)$ substrate (mostly adventitious $\mathrm{C}$ ) was removed by $\mathrm{Ar}^{+}$sputter cleaning for 5 min by applying a RF Bias of $100 \mathrm{~V}$. In the first deposition step, a $10 \mathrm{~nm}$ thick AlN layer was deposited on the substrate. Next, 20 repetitions of a bilayer unit constituting a $5 \mathrm{~nm}$ thick $\mathrm{Ag}$ layer and a $10 \mathrm{~nm}$ thick AlN barrier layer were deposited on top (Scheme 1).

\subsection{Measurements}

The phase constitution, texture and morphology of the as-deposited and thermally treated NMLs were analyzed by SEM, TEM, XRD and XPS. In addition, in situ high-temperature XRD (HT-XRD) analysis upon heating was carried out at the Swiss Light Source (SLS) synchrotron facility (PSI Villigen, Switzerland).

Electron microscopy. High-resolution SEM imaging of the samples was performed in plain view using a Hitachi S-4800 device equipped with a Bruker XFlash 6|60 energy dispersive $\mathrm{X}$-ray (EDX) detector. In order to be surface sensitive, the SEM investigations (imaging and EDX-measurements) were performed at $5 \mathrm{kV}$, which is high enough to excite the adsorption edge of both constituting elements (M-lines of $\mathrm{W}$, L-line of $\mathrm{Cu}$ ). The TEM observations have been performed using a Hitachi STEM HD2700 scanning-transmission electron microscope with an accelerating voltage of $200 \mathrm{kV}$. The TEM specimens were cut as cross-sections of the deposited layers using an NB5000 dual beam system (Hitachi High Technologies Corporation, Japan) with $\mathrm{Ga}^{+}$ion beam. In order to reduce the lamella thickness, low energy ion polishing has been employed. A GentleMill (Technoorg Linda Ltd, Hungary) device with $\mathrm{Ar}^{+}$ion beam operated at an accelerating voltage below $1 \mathrm{kV}$ has been used.

Standard and real-time X-ray diffraction. A Discover (D8) X-Ray Diffractometer from Bruker, operating in Bragg-Brentano geometry, was applied to measure theta-2-theta ( $\mathrm{t} 2 \mathrm{t}$ ) scans. In addition, texture measurements (i.e. pole figures) of the $\mathrm{Ag}(111)$ and $\operatorname{AlN}(103)$ reflections were recorded before and after heating up to $420{ }^{\circ} \mathrm{C}$ in air. The XRD data were collected in the $2 \theta$ range of $20-100^{\circ}$ with a step size of $0.02^{\circ}$ using $\mathrm{Cu} \mathrm{K} \alpha_{1-2}$ radiation $\left(\lambda_{\text {average }}=0.15418 \mathrm{~nm}, 40 \mathrm{kV}\right.$ and $\left.40 \mathrm{~mA}\right)$. 
The microstructural evolution of the NMLs was in situ monitored from room-temperature (RT) to $420{ }^{\circ} \mathrm{C}$ by real-time synchrotron XRD in the Material Science beamline (X03MA) at the SLS. The X03MA beamline is conceived to provide X-rays in the energy range of 5-40 keV for diffraction experiments. The experiments were carried out on the powder diffraction branch using a photon energy of $20 \mathrm{keV}(\lambda=0.61986 \AA)$ and a MYTHEN single-photoncounting silicon micros-trip detector, which allowed the acquisition of the diffraction patterns over $120^{\circ}$ in 2 theta in less than $40 \mathrm{~s}$. Hence, at least one 2theta spectrum was recorded every $10{ }^{\circ} \mathrm{C}$ during fast heating at a rate of up to $20{ }^{\circ} \mathrm{C} \mathrm{min}{ }^{-1}$ (a detailed description of the beamline setup and the detector is given elsewhere $\left.{ }^{28,29}\right)$. The beamline setup was equipped with a custom-designed furnace for in situ heating (HTK $16 \mathrm{MSW}$ ), especially constructed for transmission diffraction measurements at ambient pressure in air. The applied temperature ramp during in situ heating and simultaneous XRD analysis is shown in Fig. 4. First, the specimen was pre-heated up to $160{ }^{\circ} \mathrm{C}$ and thermally equilibrated for roughly $15 \mathrm{~min}$. Next, the specimen was heated up to $320{ }^{\circ} \mathrm{C}$ at an nearly constant rate of $4.6^{\circ} \mathrm{C} \mathrm{min}{ }^{-1}$ and subsequently up to $420{ }^{\circ} \mathrm{C}$ at maximum power (of the ceramic heating plate) resulting in a heating rate of $20{ }^{\circ} \mathrm{C} \mathrm{min}^{-1}$. The specimen was kept at $420{ }^{\circ} \mathrm{C}$ for $40 \mathrm{~min}$, after which the heat source was switched off, allowing the sample to freely cool down to room temperature.

X-ray spectroscopy. X-ray Photoelectron Spectroscopy (XPS) analysis was performed ex situ on both as-deposited and heattreated Ag/AlN NML samples using a Physical Electronics (PHI) Quantum 2000 setup (base pressure $<1 \times 10^{-9} \mathrm{mbar}$ ), equipped with a monochromatic $\mathrm{Al} \mathrm{K} \alpha$ anode (1486.68 eV and spot size of $100 \mu \mathrm{m}$ ) and a hemispherical electron-energy analyzer. Energy calibration was carried out before and after each set of measurements by referencing the energy scale to the $\mathrm{Au} 4 \mathrm{f}_{7 / 2}$ core level peak positioned at $84.0 \mathrm{eV}$, as measured from a sputter-cleaned Au reference sample. Composition-depth profiles were recorded by employing alternating cycles of sputtering and XPS analysis using a focused $1 \mathrm{kV} \mathrm{Ar}^{+}$ion beam rasterizing an area of $(1 \times 1) \mathrm{mm}^{2}$ at an incident angle of $45^{\circ}$. During each successive analysis step, the $\mathrm{Ag} 3 \mathrm{~d}, \mathrm{Al} 2 \mathrm{p}, \mathrm{Al} 2 \mathrm{~s}, \mathrm{~N}$ 1s, O 1s and C 1s core level spectra were recorded. Spectral reconstruction was performed by employing the linear least-squares fitting procedure of the PHI Multipack software (version 8.2). For the quantification of the thus-resolved peak intensities (areas), the relative elemental sensitivity factors supplied by the system manufacturer were employed. With this setup, an accuracy of $\sim 5 \%$ can be routinely achieved. Carbon was only detected at the outer surface (i.e. first 1-2 nm) and was therefore not considered in the quantitative XPS analysis.

\section{Results and discussion}

\subsection{NML morphology}

The Ag/AlN NMLs, as deposited on $\alpha-\mathrm{Al}_{2} \mathrm{O}_{3}(1 \overline{1} 02)$ substrates by magnetron sputtering, are constituted of a $10 \mathrm{~nm}$ thick AlN bottom layer and 20 repetitions of a unit comprising a $5 \mathrm{~nm}$ thick Ag layer and a $10 \mathrm{~nm}$ thick AlN barrier layer. SEM micrographs of the surface of the Ag/AlN NML in the as-deposited state and after heat treatment up to $420{ }^{\circ} \mathrm{C}$ in air are shown in Fig. 1a and b, respectively. Corresponding cross-sectional TEM micrographs are presented in Fig. 1c and d. It follows that the alternating Ag and AlN layers are well resolved for the as-deposited state. Notably the first as-deposited layers have a rather uniform thickness whereas successive ones progressively roughen towards the NML surface (Fig. 1c). The progressively enhanced layer roughness originates from the poor wetting of $\mathrm{Ag}$ on AlN, which hinders the formation of laterally closed $\mathrm{Ag}$ layers during successive deposition steps (by impingement and coalescence of nucleated $\mathrm{Ag}$ islands). Nonetheless, the NML surface still appears rather homogeneous on a large scale, with only some step-like corrugations due to the aforementioned island-by-layer 3D growth mode (see the inset of Fig. 1a).

Fast annealing in air up to $420{ }^{\circ} \mathrm{C}$ causes pronounced changes in the NML structure. In particular, a high density of homogeneously distributed Ag particles arises at the surface after heating (Fig. 1b and 2). These Ag particles are preferentially round-shaped, with a lateral size spanning between tenths of nanometers and about $1 \mu \mathrm{m}$. The cross-sectional TEM analysis of the heat-treated NML no longer displays a distinct contrast between successive layers (Fig. 1d), in accordance with an extensive migration of the confined $\mathrm{Ag}$ during heating in air (i.e. leaving only a minor amount of metallic filler inside the layered structure).

It is concluded that heating the Ag/AlN NML in air to $420{ }^{\circ} \mathrm{C}$ results in an extensive migration of the $\mathrm{Ag}$ filler to the outer NML surface at temperatures well below the bulk melting point of $\mathrm{Ag}\left(T_{\mathrm{m}}=962{ }^{\circ} \mathrm{C}\right)$. Strikingly, the Ag surface coverage is much less after an identical heat treatment carried out in an oxygen-deficient atmosphere (UHV) or on a bulk-like Ag layer (i.e. without a nanoconfinement of the Ag metal; see ESI, $\dagger$ Fig. S1). In the latter cases, the few Ag particles found on the surface appear remarkably smaller in size and/or number and occasionally nanowires are formed instead of spherical-shaped protrusions. Importantly, in the absence of a nano-confinement of the $\mathrm{Ag}$, as for a thick $\mathrm{Ag}$ layer (200 nm) sandwiched between two AlN barriers, nearly no metal relocate on the surface after annealing in air (see ESI, $\dagger$ Fig. S1b). These experimental findings suggest that the thermally activated mass transport of $\mathrm{Ag}$ from the NML interior to the outer surface is promoted and driven by the combined effects of nano-confinement and an O-rich processing atmosphere. To disclose the underlying mechanism(s) for Ag migration, a detailed microstructural analysis of the as-deposited and heat-treated Ag/AlN NMLs was performed by applying a combinatorial analytical approach using ex situ XRD (using laboratory setups), in situ real-time transmission XRD (at the synchrotron facility) and ex situ XPS analysis (both chemical state analysis and sputter-depth profiling), as discussed in the following.

\subsection{Microstructure and texture}

Fig. 3a shows the diffractograms of the as-deposited and heattreated Ag/AlN NMLs, as measured ex situ in Bragg-Brentano geometry. For the as-deposited state (black spectrum), the most intense reflections appear as typical superlattice (multi) peaks due to the periodic NML structure. This superlattice structure is 


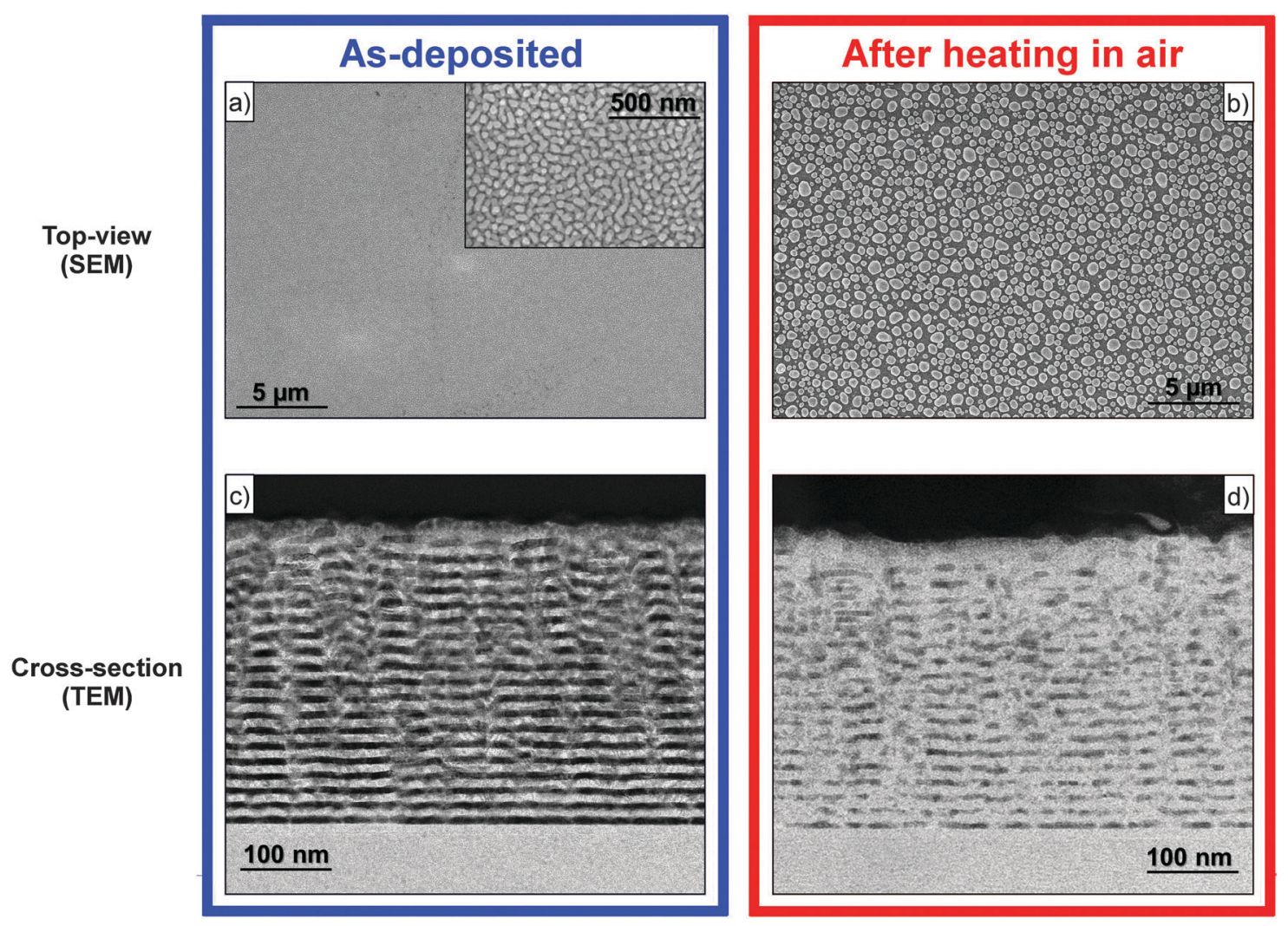

Fig. 1 SEM images (in planar view) of the Ag/AIN NML in the (a) as-deposited state (inset: higher magnification) and (b) after heating up to $420{ }^{\circ} \mathrm{C}$ in air (cf. SEM carried out on the same sample heated in UHV, Fig. S1 in the ESI†). A high density of Ag particles is found on the NML surface. Corresponding cross-sectional TEM images are given in (c) and (d), respectively.

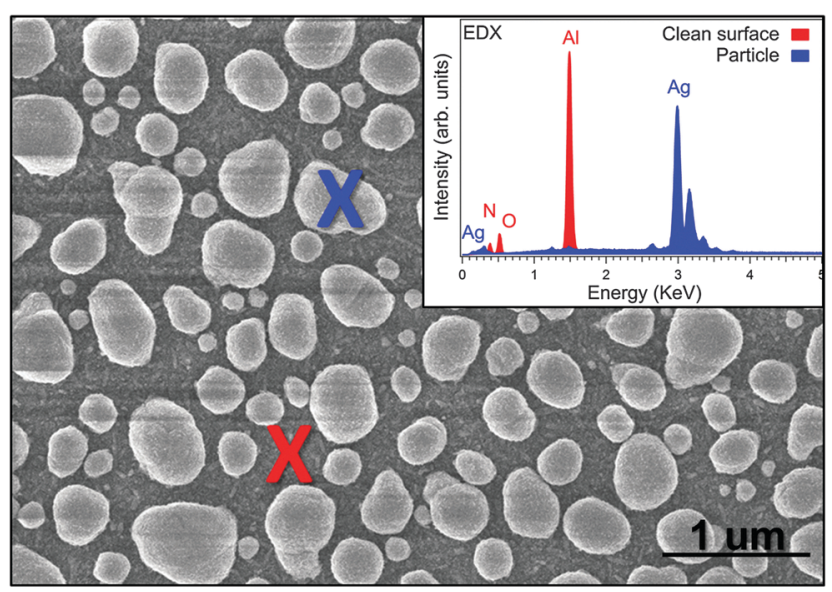

Fig. 2 SEM/EDX analysis of the Ag/AIN NML surface after heating in air up to $420{ }^{\circ} \mathrm{C}$ (cf. Fig. S1 in the ESI†). The EDX spectra (inset) indicate that the particles are mainly composed of Ag.

found in the $2 \theta=32^{\circ}-42^{\circ}$ region, indicating preferred $\mathrm{Ag}[111]$ and AlN[001] growth directions during sputter deposition. This is expected, since the $\mathrm{Ag}\{111\}$ and $\operatorname{AlN}\{001\}$ planes constitute the most densely packed planes of lowest surface energy. ${ }^{30}$ Additional $\mathrm{Ag}(200)$ and $\mathrm{Ag}(220)$ reflections with much lower intensities and broad profiles are detected at $2 \theta \sim 44^{\circ}$ and $\sim 65^{\circ}$, respectively. This indicates that the as-deposited Ag/AlN
NML is not an ideal stacking of single-oriented Ag planes, but also contains a (small) fraction of randomly oriented crystallites.

The superlattice (multi) peaks arise from the periodic NML structure. ${ }^{31}$ This region of the diffractogram was theoretically calculated on the basis of a kinematic formalism which included $\mathrm{Ag}\langle 111\rangle$ and $\mathrm{AlN}\langle 001\rangle$ textures with interface disorder. The observed satellite peaks are well reproduced within the model, allowing an estimation of the $\mathrm{Ag} / \mathrm{AlN}$ bilayer unit thickness of $13.5 \mathrm{~nm}$, in good agreement with the nominal value of $15 \mathrm{~nm}$ (for a detailed description of this computation, see ESI, $\dagger$ Fig. S2). The aforementioned $\mathrm{Ag}[111]$ and $\mathrm{AlN}[001]$ preferred growth directions were also confirmed by pole figure measurements of Ag $\{111\}$ and AlN $\{103\}$ : see Fig. 3b and c. Both the $A g\{111\}$ and $\operatorname{AlN}\{103\}$ pole figures exhibit a six-fold symmetry, which indicates the existence of an epitaxial relationship between the alternating $\mathrm{Ag}$ and AlN layers (i.e. both in-plane and out-ofplane texture). In the $A g\{111\}$ pole figure (Fig. $3 b$ ), the angle between the central pole and the secondary ones is $\Psi \sim 70.5^{\circ}$, which matches the expected angle between equivalent planes belonging to $\operatorname{Ag}\{111\}$. In the $\operatorname{AlN}\{103\}$ pole figure (Fig. 3c), the angle between the central pole and the secondary poles is $\Psi \sim 31^{\circ}$ (indicated by a dashed white ring), corresponding to the angle between the AlN $\langle 001\rangle$ and $\operatorname{AlN}\langle 103\rangle$ directions. It follows that the alternating $\mathrm{Ag}$ and AlN layers obey an epitaxial orientation relationship according to $\operatorname{Ag}\{111\}\langle 10 \overline{1}\rangle|| \operatorname{AlN}\{001\}\langle 100\rangle$, as also reported in ref. 19. 

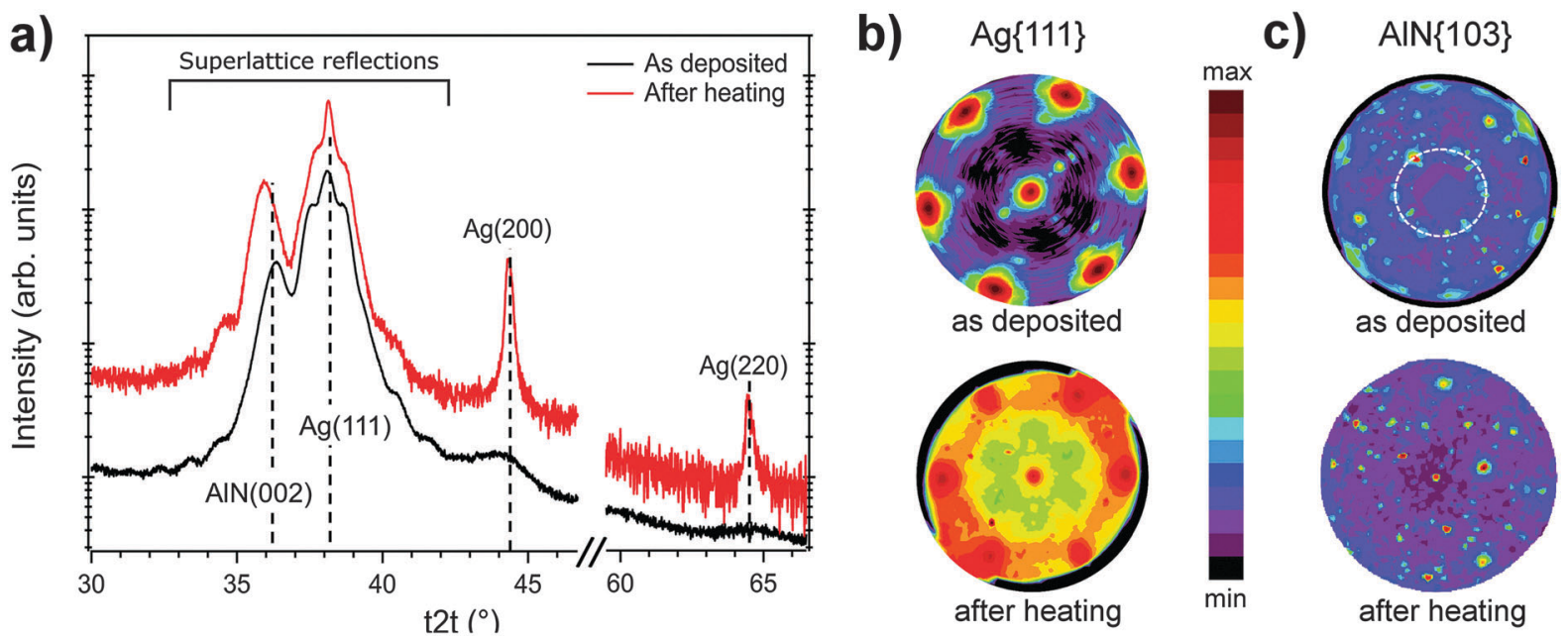

Fig. 3 (a) Theta-2theta (t2t) XRD scans of the Ag/AIN NML before (black) and after (red) heat treatment in air up to $420{ }^{\circ} \mathrm{C}, 2 \theta$ positions of selected Ag and AIN reflections are reported in dashed lines - pole figures for (b) Ag\{111\} and (c) AIN $\{103\}$ family of planes, as recorded from the Ag/AIN NMLs before and after heat treatment in air up to $420^{\circ} \mathrm{C}$. For the AIN $\{103\}$ pole figure, a dashed circle indicates the angular position of AIN\{001\}.

After heat treatment in air up to $420{ }^{\circ} \mathrm{C}$, the $\mathrm{Ag}(111), \mathrm{Ag}(200)$ and $\mathrm{Ag}(220)$ reflections in the measured theta-2theta (t2t) scans significantly increase in intensity and approximately match the expected reciprocal ratios for bulk polycrystalline $\mathrm{Ag}$ (red spectrum in Fig. 3a). Still the Ag/AlN superlattice modulation is partially maintained, suggesting that the nano-laminated structure is to some extent preserved after the heat treatment, in accordance with the cross-sectional TEM analysis (Fig. 1). Moreover, Ag $\{111\}$ pole figure measurements show an overall decrease of the six-fold Ag $\{111\}$ intensity poles (see Fig. $3 b$ ), indicating a partial loss of in- and out-of-plane texture of $\mathrm{Ag}$ upon heating. This implies that the Ag particles that are formed at the NML surface during heating (by extensive outward migration; $c f$. Fig. 1) adopt a more random orientation as compared to the highly textured Ag nanograins inside the NML. The increased contribution of randomly orientated Ag crystals to the diffracted intensity also results in a substantial increase of the background intensity in the $\mathrm{Ag}\{111\}$ pole figure after heating (Fig. 3b). The corresponding texture measurements for the AlN $\{103\}$ family of planes also indicate a partial loss of the primary AlN $\langle 001\rangle$ texture after heating. Interestingly, the measured t2t scan of the heat-treated NML (Fig. 3a) does not exhibit distinct changes of the AlN diffraction pattern after annealing up to $420{ }^{\circ} \mathrm{C}$ : besides superlattice peaks, no additional AlN reflections arise after heating. This may indicate the formation of an amorphous reaction product within the AlN barrier layers upon heating, as will be discussed in more detail below.

\subsection{Stress evolution during heating by real-time transmission-XRD}

The microstructural evolution of the Ag/AlN NML during annealing in air up to $420^{\circ} \mathrm{C}$ and subsequent cooling was monitored by realtime XRD collected in the transmission mode using synchrotron radiation $(\lambda=0.61986 \AA$ and $h \nu=20 \mathrm{keV})$. The corresponding realtime XRD map during heating is shown in Fig. 4, as constructed by stacking the measured 2theta scans as a function of time.
The corresponding temperature ramp followed during the treatment is presented in the right panel of Fig. 4. Fig. 5 shows the changes of the Full Width Half Maximum (FWHM) of $\operatorname{Ag}(222)$ and $\operatorname{AlN}(100)$ diffraction peaks, respectively. Moreover, the size of the coherently diffracting domains (coherency length) for $\mathrm{Ag}$ and $\mathrm{AlN}$ is also reported (as estimated on the basis of the Scherrer formula; see below).

As follows from Fig. 4, only the $\mathrm{Ag}(111), \mathrm{Ag}(311)$ and $\mathrm{Ag}(222)$ reflections are detected in the as-deposited sample, as attributed to the primary texture of the confined Ag layers ( $c f$. Fig. 3b). Up to $250^{\circ} \mathrm{C}$, the recorded diffractograms show no significant changes and the resolved FWHMs and the estimated coherency length of $\mathrm{Ag}$ grains are approximately constant (Fig. 5). The initial coherency length of Ag domains of $\sim 6 \mathrm{~nm}$ from room temperature (RT) up to $250^{\circ} \mathrm{C}$, as well as the nearly constant coherency length of AlN domains of $\sim 9 \mathrm{~nm}$ from RT up to $420{ }^{\circ} \mathrm{C}$, is approximately equivalent to the $\mathrm{Ag}$ and AlN layer thicknesses in the as-deposited state. Strikingly, as soon as the temperature reaches $\sim 250{ }^{\circ} \mathrm{C}$, all the reflections associated with polycrystalline $\mathrm{Ag}$ gradually appear, which is accompanied by (i) a strong decrease of the $\mathrm{Ag}(222)$ FWHM and (ii) a strong increase of the average Ag domain size from $\sim 6 \mathrm{~nm}$ at RT to $160 \mathrm{~nm}$ at $420{ }^{\circ} \mathrm{C}$ (Fig. 4 and 5). The decrease of the $\mathrm{Ag}(222) \mathrm{FWHM}$ (and the corresponding simultaneous increase of the Ag domain size) suggests a domain coarsening by Ag grain-growth. Noteworthily, the decrease of the AlN(100) FWHM and simultaneous increase of the AlN domain size from RT to $420^{\circ} \mathrm{C}$ is much less pronounced; that is, the FWHM decreases from $0.33^{\circ}$ to $0.29^{\circ}$ corresponding to a relatively small increase of the average domain size from $\sim 9 \mathrm{~nm}$ to $\sim 12 \mathrm{~nm}$, respectively; see Fig. 5. Thus, these experimental findings evidence the migration of the confined $\mathrm{Ag}$ atoms to the NML surface at a temperature as low as $250{ }^{\circ} \mathrm{C}$. Indeed, as confirmed by the SEM analysis (Fig. 1b), a large density of metallic $\mathrm{Ag}$ particles is present on the surface after heating up to $420^{\circ} \mathrm{C}$. The Ag particles can coarsen at a much higher rate at the free surface as compared to the (remaining) confined Ag nano-grains within the NML. 


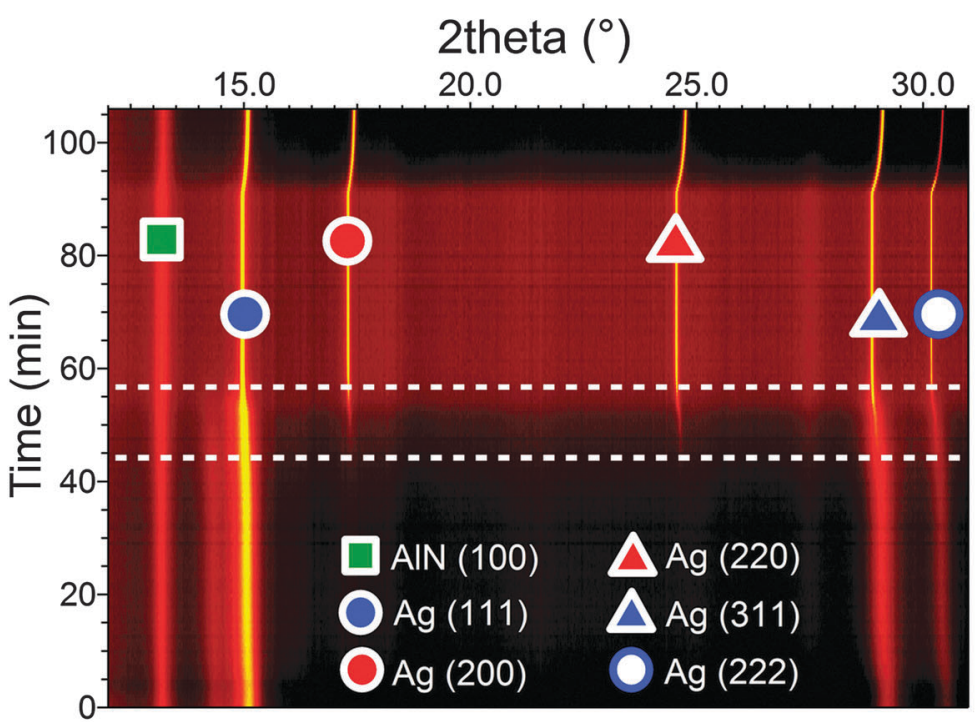

\section{Temperature $\left({ }^{\circ} \mathrm{C}\right)$ \\ $0 \quad 100200300400$}

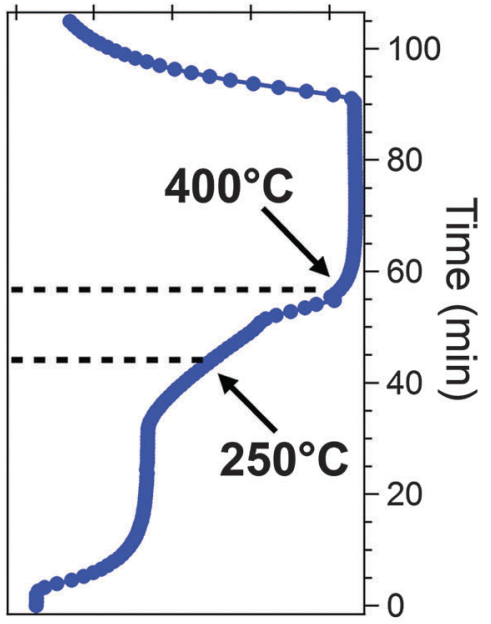

Fig. 4 Real-time XRD map of the Ag/AIN NML during heating in air, as constructed by stacking the measured 2theta scans as a function of processing time. The corresponding course of the sample temperature as a function of heating time is presented in the right panel. Notably all the reflections ascribed to polycrystalline Ag gradually appear at $T>250{ }^{\circ} \mathrm{C}$, as attributed to the extensive outflow of $\mathrm{Ag}$ to the NML surface (cf. Fig. 1).

As follows from recent thermodynamic predictions of the phase stability of nano-confined layered metals, ${ }^{27}$ the reduction

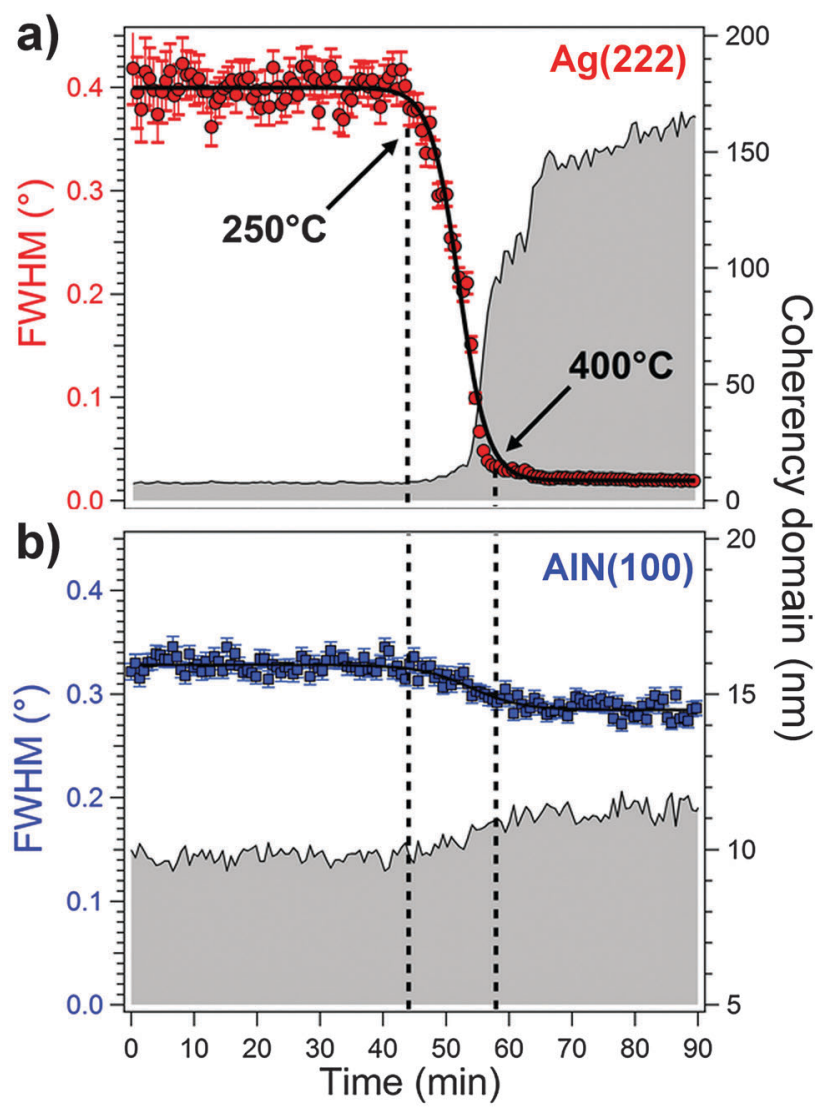

Fig. 5 Evolutions of the FWHMs of the Ag(222) and the AIN(100) diffraction peaks as a function of heating time of the Ag/AIN NML during heating in air, as resolved from the recorded diffractograms in Fig. 4. Qualitative estimates of the grain sizes of Ag and AIN as a function of heating time are also presented (grey area). of internal boundaries or, more specifically, the reduction of the sum of grain-boundary, interface and surface (excess) energies to the total Gibbs energy of the system, provides the dominant driving force for the migration from a NML interior to the free surface upon heating. In our work, as evidenced from the microscopic and XRD analysis (see Fig. 1-5), the migration of $\mathrm{Ag}$ towards the surface becomes thermally activated at around $200{ }^{\circ} \mathrm{C}$, but again decelerates at around $400{ }^{\circ} \mathrm{C}$. This suggests that besides the reduction of the sum of grain-boundary, interface and surface energies, an additional mechanism for Ag outward migration is active in the temperature range $200{ }^{\circ} \mathrm{C}<T<$ $400{ }^{\circ} \mathrm{C}$, which ceases at temperatures $T>400{ }^{\circ} \mathrm{C}$. Considering the large differences in thermal expansion coefficients between the $\mathrm{Al}_{2} \mathrm{O}_{3}$ substrate and the $\mathrm{Ag}$ and AlN layers, the accumulation and subsequent relaxation of thermally-induced stress gradients in the NML upon heating could promote directional Ag migration. ${ }^{20,32}$ Namely the relaxation of thermal stresses can be easily achieved at the free surface, but not at the interface. Indeed directional (inward) migration of $\mathrm{Ag}$ to the $\mathrm{NML} /$ substrate has not been observed in the present study.

To investigate the stress evolution of the NML during heating and subsequent cooling, the $\mathrm{Ag}(111)$ and $\mathrm{Ag}(222)$ diffraction peaks in the real-time XRD data set were analyzed using the Uniform Stress Deformation Model, ${ }^{33}$ as described in more details in the ESI. $\dagger$ In addition, the measured changes of the $\operatorname{Ag}\{222\}$ and $\operatorname{AlN}\{100\}$ lattice spacings are reported as a function of temperature.

Although the USDM method for stress evaluation is rather crude, distinct changes in the residual stress state of $\mathrm{Ag}$ can be observed in the temperature range from $170{ }^{\circ} \mathrm{C}$ to $400{ }^{\circ} \mathrm{C}$, see Fig. 6. In the as-deposited state, the confined $\mathrm{Ag}$ layers have an average compressive residual stress of about $100 \mathrm{MPa}$. The initial compressive stress state of the confined $\mathrm{Ag}$ layers mainly originates from accumulated growth stresses during the sputter 


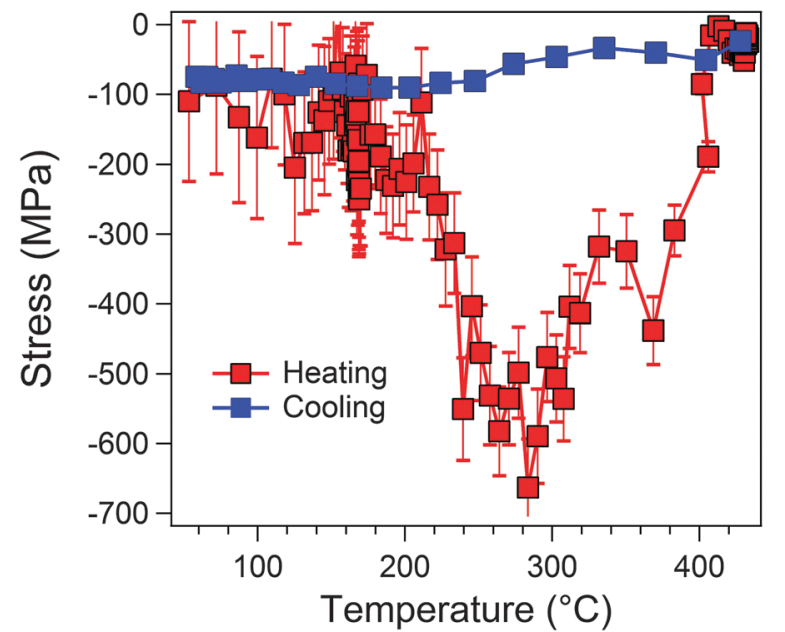

Fig. 6 Calculated average residual stress in $\mathrm{Ag}$ as a function of temperature, as determined from the $\mathrm{Ag}(111)$ and $\mathrm{Ag}(222)$ diffraction peaks in the real-time XRD data set of Fig. 5 using the Uniform Stress Deformation Model (USDM).

deposition process and interface stresses due to the lattice mismatch between AlN and Ag. Since the thermal expansion of bulk (unstrained) silver $\left(\alpha_{\mathrm{Ag}} \approx 19{ }^{\circ} \mathrm{C}^{-1}\right)^{34}$ is significantly larger than that of the $\alpha-\mathrm{Al}_{2} \mathrm{O}_{3}$ substrate $\left(\alpha_{\text {sapphire }} \approx 8{ }^{\circ} \mathrm{C}^{-1}\right),{ }^{35}$ additional compressive stresses should be generated in the confined Ag upon heating. However, during the first stage of heating up to about $200{ }^{\circ} \mathrm{C}$, the compressive stress state of the confined Ag remains relatively constant (Fig. 6), which suggests that compressive stress generation by the thermal expansion mismatch is probably counteracted by tensile stress generation due to the annihilation of growth defects (and possibly also by the annihilation of grain boundaries due to domain coarsening ${ }^{20,36}$ ). The expected accumulation of compressive stresses in the confined Ag layers (due to the thermal expansion mismatch) proceeds in the temperature range of $200{ }^{\circ} \mathrm{C}<T<280^{\circ} \mathrm{C}$. The accumulated compressive stresses reach a maximum value of $\sigma=-650 \mathrm{MPa}$ at $280{ }^{\circ} \mathrm{C}$. However, the accumulated stresses become fully relaxed upon further heating in the range $280{ }^{\circ} \mathrm{C}<T<400{ }^{\circ} \mathrm{C}$, which runs parallel with the observed migration of the confined Ag to the NML surface (Fig. 1). At $T>400{ }^{\circ} \mathrm{C}$, as well as during subsequent cooling, the $\mathrm{Ag}$ metal maintains an essentially stress-free state (reaching a final stress of around $-80 \mathrm{MPa}$ after cooling down to RT). This is not surprising, since during heating up to $420^{\circ} \mathrm{C}$, a large amount of $\mathrm{Ag}$ is relocated as particles on the NML surface (cf. Fig. 1), which can nearly freely contract in a bulk-like manner during subsequent cooling (without being affected by the NML confinement and/or the thermal shrinkage of the $\alpha-\mathrm{Al}_{2} \mathrm{O}_{3}$ substrate). Indeed the linear thermo-elastic slope of the $\mathrm{Ag}\{222\}$ $d$-spacing during cooling complies well with the linear thermal expansion coefficient of bulk, unstrained Ag (Fig. 7a).

It may be assumed that the creation of free volume and pores within the NML by Ag outward migration (as experimentally observed for heat-treated $\mathrm{AgCu} / \mathrm{AlN} N \mathrm{NLs}^{37}$ ) aids the relaxation of residual stresses in the AlN barrier layers. Indeed, during the first stage of heating up to $250{ }^{\circ} \mathrm{C}$, the $\operatorname{AlN}(100) d$-spacing increases
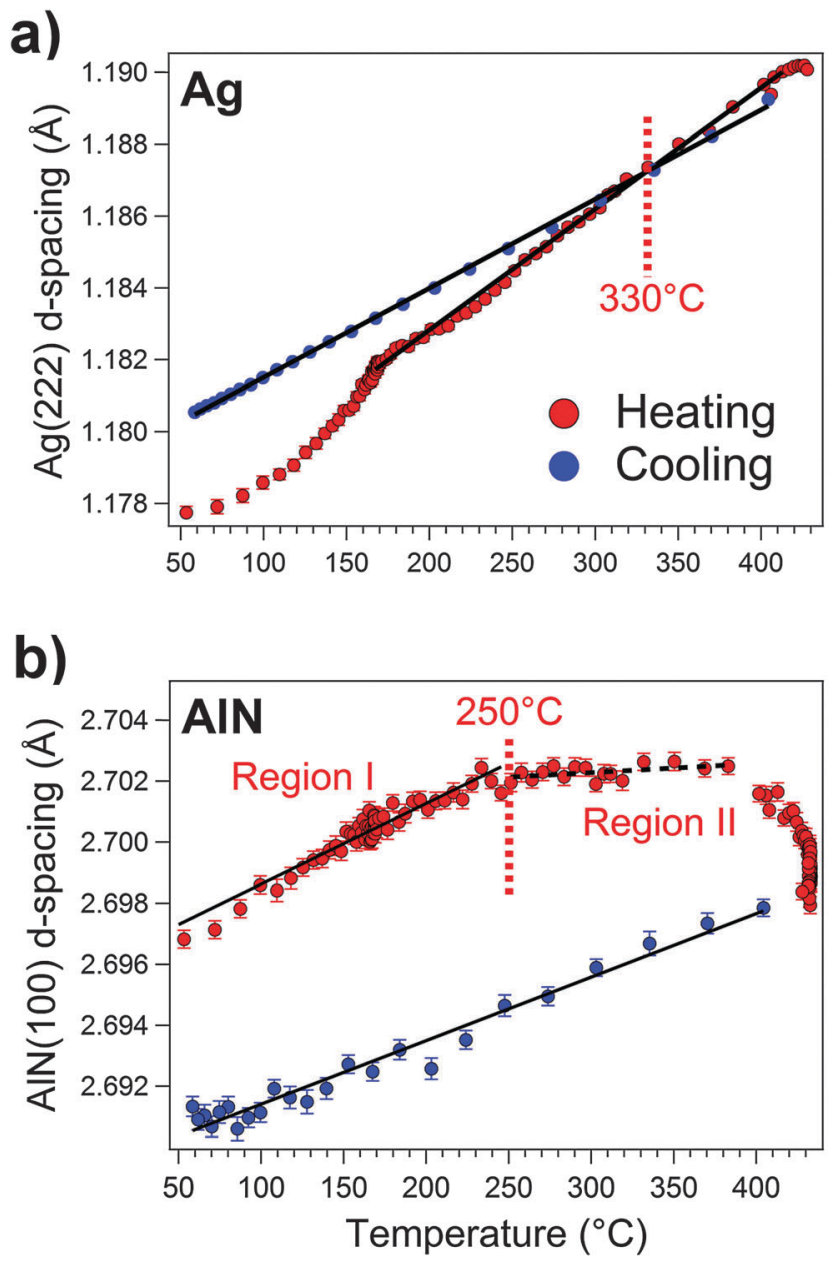

Fig. 7 Evolutions of the $\operatorname{Ag}(222)$ (a) and $\operatorname{AlN}(100)$ (b) $d$-spacings as a function of temperature, as resolved from the recorded diffractograms of the Ag/AIN NML during heating in air (Fig. 4).

approximately linearly with a thermal expansion of $\alpha_{\mathrm{AlN}}=$ $9.7^{\circ} \mathrm{C}^{-1}$, which is much larger than that of bulk (unstrained) AlN $\left(5{ }^{\circ} \mathrm{C}^{-1}\right),{ }^{35}$ but close to that of bulk $\alpha-\mathrm{Al}_{2} \mathrm{O}_{3}\left(8{ }^{\circ} \mathrm{C}^{-1}\right)$ : see Fig. 7b. For $T>250{ }^{\circ} \mathrm{C}$, the linear thermal expansion becomes much lower (i.e. $\alpha_{\text {AlN }}=3.3{ }^{\circ} \mathrm{C}^{-1}$ ), indicating a (partial) relaxation of thermal stresses in the AlN barrier layers during Ag outward migration. Isothermal annealing at $420{ }^{\circ} \mathrm{C}$ results in a further decrease of the AlN $\{100\}$ spacing towards the reference value of $2.698 \AA$ for unstrained bulk AlN at $420{ }^{\circ} \mathrm{C}$, indicating a stressfree state of the AlN. The AlN barrier layers still adhere to the (infinitely thicker) $\alpha-\mathrm{Al}_{2} \mathrm{O}_{3}$ substrate upon heating up to $420{ }^{\circ} \mathrm{C}$. Consequently, the shrinkage of the AlN barrier layers during cooling is dictated by the $\alpha-\mathrm{Al}_{2} \mathrm{O}_{3}$ substrate (i.e. the linear thermal expansion of AlN during cooling follows that of the $\alpha-\mathrm{Al}_{2} \mathrm{O}_{3}$ substrate: $\alpha_{\text {AIN }}=7.8{ }^{\circ} \mathrm{C}^{-1}$ versus $\alpha_{\text {sapphire }} \approx 8{ }^{\circ} \mathrm{C}^{-1}$ ): see Fig. $7 \mathrm{~b}$.

Although compressive stress relaxation by Ag outflow ceases at $T \approx 400{ }^{\circ} \mathrm{C}$, the $\operatorname{Ag}(222)$ FWHM still continues to decrease upon further heating, which indicates further coarsening of $\mathrm{Ag}$ surface particles during isothermal annealing. This supports our previous statement (see also ref. 27) that the reduction of the sum of grain-boundary, interface and surface energies provides the 
main driving force for $\mathrm{Ag}$ migration and grain coarsening up to $420{ }^{\circ} \mathrm{C}$. Thus, it is concluded that compressive stress relaxation is active as an (additional) driving force for $\mathrm{Ag}$ outward migration in the temperature range of $280{ }^{\circ} \mathrm{C}<T<400{ }^{\circ} \mathrm{C}$.

\subsection{Chemical driving force: the role of oxygen in $\mathrm{Ag} / \mathrm{AlN}$ thermal evolution}

The main driving forces and underlying mechanisms for the outward migration of confined $\mathrm{Ag}$ at temperatures as low as $200{ }^{\circ} \mathrm{C}$ have been elucidated above. However, it still remains unclear why the Ag mobility is hugely enhanced upon heating in air as compared to heating under UHV ( $c f$. ESI, $\dagger$ Fig. S1). To identify the prominent role of oxygen in enhancing the mobility of $\mathrm{Ag}$ at such low temperatures, an extensive chemical state investigation by XPS was conducted as follows.

Fig. 8a shows a composition-depth profile of the as-deposited $\mathrm{Ag} / \mathrm{AlN}$ NML, as obtained by XPS sputter-depth profiling. The laminated structure of the Ag/AlN NML in the as-deposited state results in regular oscillations of the measured atomic concentrations of $\mathrm{Ag}, \mathrm{Al}$ and $\mathrm{N}$ as a function of depth. The characteristic damping of the oscillating $\mathrm{Ag}, \mathrm{Al}$ and $\mathrm{N}$ concentrations with increasing sputter depth (Fig. 8a) is generally attributed to the following superimposed sputter-induced artifacts: (i) an enhanced degree of intermixing with increasing sputter depth, (ii) an increase of sputter-induced roughness with increasing sputter depth and (iii) the preferential sputtering of $\mathrm{Ag}$ (due to the much lower surface binding energy of $\mathrm{Ag}$ as compared to that of AlN; i.e. $E_{\mathrm{b}}=3.1 \mathrm{eV}$ versus $E_{\mathrm{b}}=9.1 \mathrm{eV}$, respectively ${ }^{38}$ ). Due to these superimposed sputter artifacts, the measured atomic concentration of $\mathrm{Ag}$ within the successive Ag layers progressively decreases with increasing sputter depth towards a steady-state $\mathrm{Ag}$ concentration of 20 at $\%$ (Fig. 8a). The XPS analysis confirms that the NML is composed of pure Ag metal and pure AlN with minor surface contaminations of $\mathrm{O}$ and adventitious $\mathrm{C}$. After the first few sputter cycles, the $\mathrm{O} 1 \mathrm{~s}$ and C 1s signal intensities drop below the detection limit, indicating that the $\mathrm{O}$ and $\mathrm{C}$ contaminations originate from air exposure after the sample removal from the high-vacuum sputter-deposition chamber. The measured XPS spectra of the $\mathrm{Ag} 3 \mathrm{~d}, \mathrm{Al} \mathrm{2p}$ and $\mathrm{N}$ 1s core-level regions after 80 minutes of $\mathrm{Ar}^{+}$sputtering are shown in Fig. 8b-d. The measured Ag 3d XPS in Fig. 8b shows the 5/2-3/2 spin-orbit doublet with a splitting of $6 \mathrm{eV}$ (i.e. $374.3-368.3 \mathrm{eV}$ ) and a strong plasmon loss at a binding energy (BE) of around $372.2 \mathrm{eV}$, which are typical of pure $\mathrm{Ag}$ metal (further designated as $\left.\mathrm{Ag}^{0}\right) \cdot{ }^{39} \mathrm{In}$ the as-deposited state, no additional components at the lower-BE side of the $\mathrm{Ag} 3 \mathrm{~d}_{5 / 2}$ main peak, indicative of $\mathrm{Ag}_{2} \mathrm{O}$ or $\mathrm{AgO}$ chemical species, ${ }^{40}$ were detected. Both the $\mathrm{Al} 2 \mathrm{p}$ and $\mathrm{N} 1 \mathrm{~s}$ spectra also constitute a single main peak centered at $74.3 \mathrm{eV}$ and $397.3 \mathrm{eV}$, respectively, characteristic of O-free AlN. ${ }^{41}$

Bulk AlN is known for its high thermal stability and chemical inertness up to elevated temperatures (about $800{ }^{\circ} \mathrm{C}$, where oxidation advances). ${ }^{42}$ However, AlN surfaces are much more reactive toward oxygen and can be easily converted to amorphous $\mathrm{Al}_{2} \mathrm{O}_{3}$ in air (even at $\mathrm{RT}$ ) for pristine ceramic thicknesses in the nanometer range. ${ }^{43-45}$ As evidenced from the cross-sectional TEM analysis (Fig. 1), the alternating Ag and AlN layers progressively roughen towards the surface, resulting in a significant number of defects, voids and grain boundaries within the Ag/AlN NML, which may act as defective channels for fast inward diffusion of oxygen species during annealing in air. $^{46-48}$ Hence, annealing of the $\mathrm{Ag} / \mathrm{AlN} \mathrm{NML}$ at ambient pressures probably not only induces oxidation of the top (i.e. surface-adjacent) AlN layer, but also of AlN barrier layers at larger depths below the surface. The composition-depth profiles of the $\mathrm{Ag} / \mathrm{AlN} \mathrm{NML}$ after annealing in air (for $30 \mathrm{~min}$ ) at $200{ }^{\circ} \mathrm{C}, 250{ }^{\circ} \mathrm{C}, 300{ }^{\circ} \mathrm{C}$ and $420{ }^{\circ} \mathrm{C}$ (as measured by XPS sputterdepth profiling) are presented in Fig. 9a-d. The XPS analysis indeed evidences deep penetration of $\mathrm{O}$ inside the NML upon annealing in air. The $\mathrm{O}$ surface concentration is in the range of 10-20 at\% after the various annealing steps (from 200 to $420{ }^{\circ} \mathrm{C}$ ). For annealing temperatures of $200{ }^{\circ} \mathrm{C}, 250{ }^{\circ} \mathrm{C}$, $300{ }^{\circ} \mathrm{C}$, the $\mathrm{O}$ concentration rapidly levels off with increasing sputter depth and attains a constant $\mathrm{O}$ concentration of about 8 at $\%, 11$ at $\%$ and 18 at\% in the interior of the NML, respectively (Fig. 9a-c). In contrast, at an annealing temperature of $420{ }^{\circ} \mathrm{C}$, the O concentration increases with increasing sputter depth and attains a much higher concentration of 34 at\% within the NML. Strikingly, the concentration of $\mathrm{O}$ with increasing sputter depth at $420{ }^{\circ} \mathrm{C}$ follows the profiles of $\mathrm{Al}$ and $\mathrm{N}$ concentrations, which evidences a preferential chemical reaction of $\mathrm{O}$ with the AlN barrier layers. The $\mathrm{Ag}, \mathrm{Al}$ and $\mathrm{N}$ oscillations become increasingly damped with increasing annealing temperature (as compared to the as-deposited state) due to the enhanced migration of Ag to the NML surface, which is especially evident in the composition-depth profiles at $300{ }^{\circ} \mathrm{C}$ and $420{ }^{\circ} \mathrm{C}$.
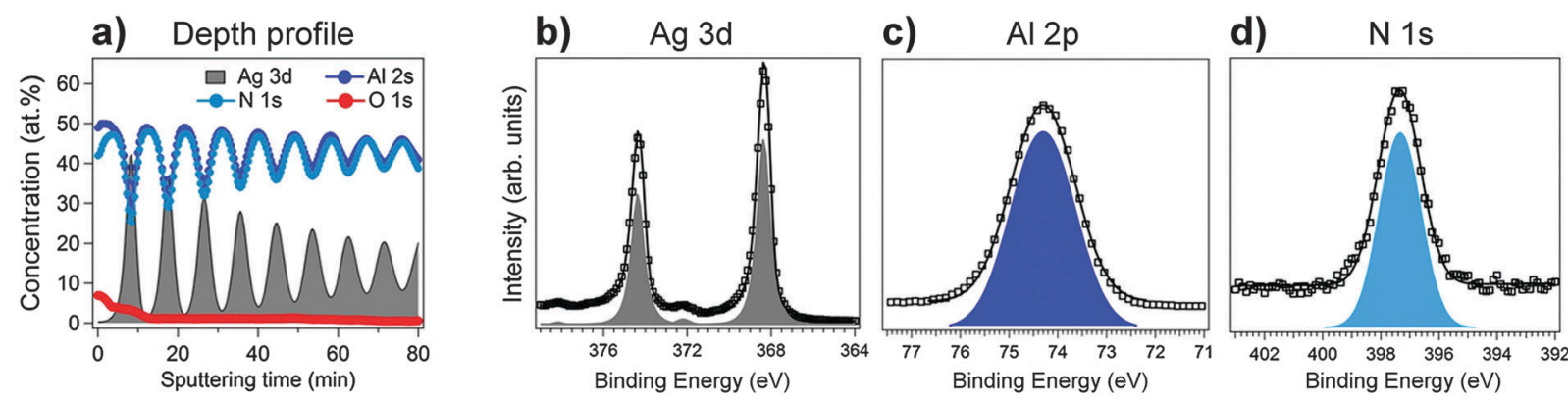

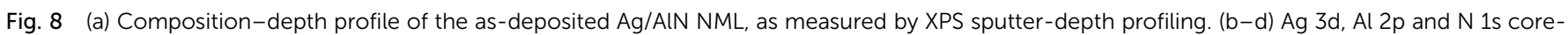

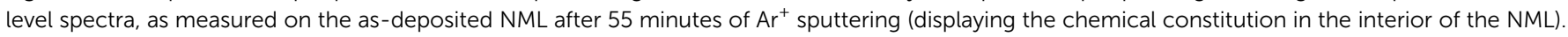



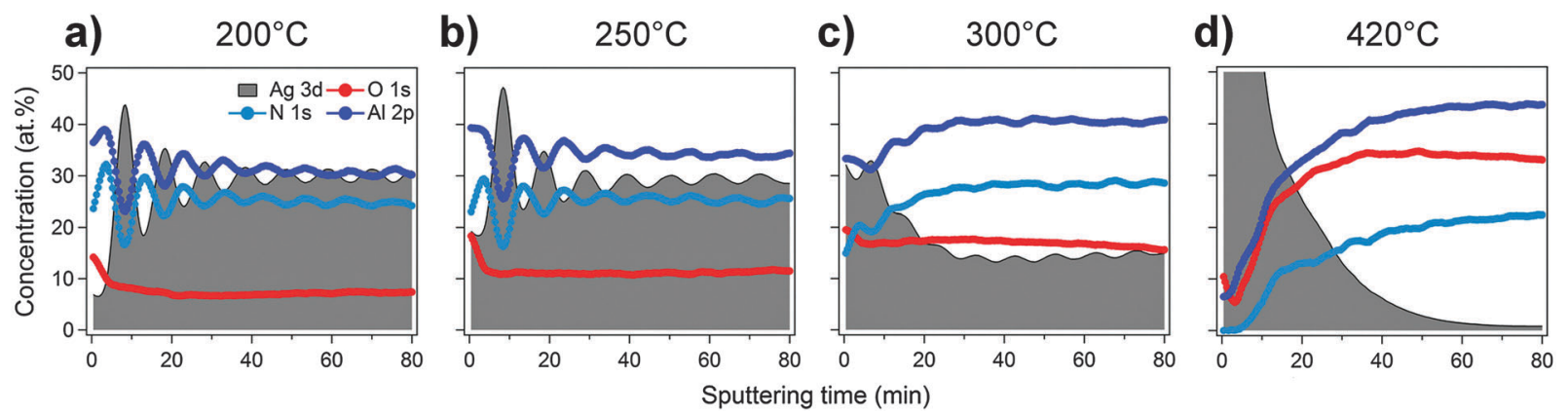

Fig. 9 XPS composition-depth profiles of the Ag/AIN NML after annealing for 30 minutes at (a) $200{ }^{\circ} \mathrm{C}$, (b) $250{ }^{\circ} \mathrm{C}$, (c) $300{ }^{\circ} \mathrm{C}$ and (d) $420{ }^{\circ} \mathrm{C}$.

Next high-resolution XPS measurements were carried out on the heated and sputtered (sputtering time: $80 \mathrm{~min}$ ) specimens in order to investigate the chemical evolution of the inner part of the NMLs after heating in air. The spectral reconstruction of the measured $\mathrm{Al}$ $2 p$ core-level region for different annealing temperatures (Fig. 10a) indicates the appearance of an oxidic $\mathrm{Al} 2 \mathrm{p}$ peak at $\mathrm{BE}=75.6 \mathrm{eV}$ due to the formation of an Al-oxide phase. ${ }^{49-51}$ The oxidic $\mathrm{Al} 2 \mathrm{p}$ intensity increases with increasing annealing temperature. The co-formation of Al-O-N ternary compounds during annealing can be neglected, since it would give rise to an additional $\mathrm{Al} 2 \mathrm{p}$ main peak at $\mathrm{BE} \approx$ $76.2 \mathrm{eV}$, as well as additional $\mathrm{N} 1 \mathrm{~s}$ main peaks at $\mathrm{BE} \approx 398.4 \mathrm{eV}$ and/ or $\mathrm{BE} \approx 402.2 \mathrm{eV},{ }^{49,52,53}$ which are not observed. The $\mathrm{Al}_{2} \mathrm{O}_{3}$ phase formed from the reaction of $\mathrm{O}$ and AlN should be predominantly amorphous, since no oxide-related reflections could be detected in the XRD analysis, in accordance with ref. 43-45.

The spectral reconstructions of the measured O1s spectra after annealing at different temperatures in air reveal a minimum of three different chemical states of $\mathrm{O}$ within the reacted
NML (Fig. 10b): i.e. (i) one dominant $\mathrm{O} 1 \mathrm{~s}$ peak at $\mathrm{BE}=532.3 \mathrm{eV}$, attributed to $\mathrm{Al}_{2} \mathrm{O}_{3}$, which is most evident after annealing at 200-300 ${ }^{\circ} \mathrm{C}^{49-51}$ (ii) a second, much weaker $\mathrm{O} 1$ s peak at $\mathrm{BE}=$ $530.8 \mathrm{eV}$ and (iii) a third $\mathrm{O} 1 \mathrm{~s}$ peak at $\mathrm{BE}=528.0 \mathrm{eV}$, which is only observed at the highest annealing temperature of $420{ }^{\circ} \mathrm{C}$. The origin of the weaker $\mathrm{O} 1 \mathrm{~s}$ peaks at $530.8 \mathrm{eV}$ and $\mathrm{BE}=$ $528.0 \mathrm{eV}$ can be rationalized by considering the reported chemical interaction of $\mathrm{O}$ with $\mathrm{Ag}$, as follows. Different chemical species can form on $\mathrm{Ag}$ surfaces after $\mathrm{O}$ exposure: adsorbed oxygen $\left(\mathrm{O}_{\mathrm{ads}}\right)$, strongly bonded chemisorbed oxygen $\left(\mathrm{O}_{\text {chem }}\right)$, as well as oxygen incorporated in the subsurface region primarily through fast diffusion paths like grain boundaries $\left(\mathrm{O}_{\text {diss }}\right) .{ }^{39,54,55} \mathrm{O}_{\text {ads }}$ species are found at $\mathrm{RT}$, while the incorporation of $\mathrm{O}$ requires a higher thermal activation and, consequently, is observed towards higher temperatures (usually beyond $200{ }^{\circ} \mathrm{C}$ ). At even higher temperatures (i.e. $T>500{ }^{\circ} \mathrm{C}$ ), the $\mathrm{O}_{\text {diss }}$ species disappear by forming stronger chemically bonded $\mathrm{O}_{\text {chem }}$ species at the surface. ${ }^{39,55,56}$ Unfortunately, the different chemical species a)

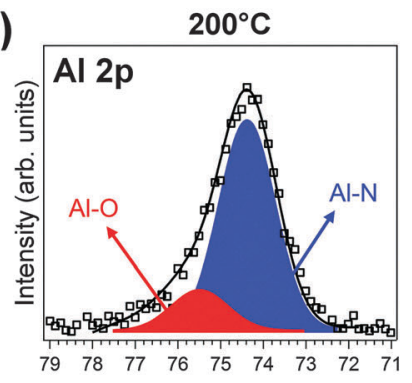

b)

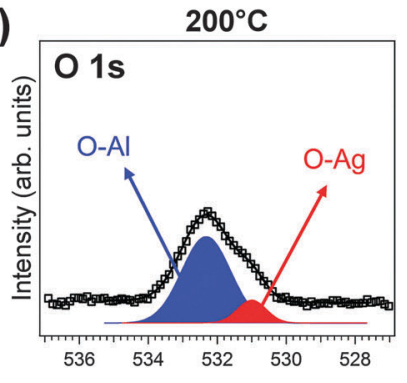

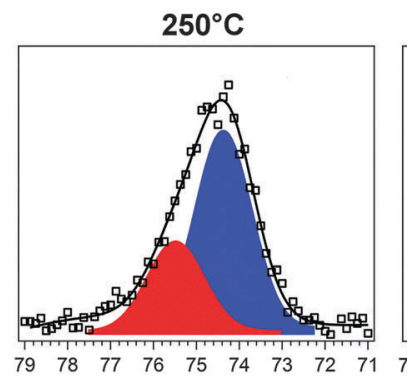
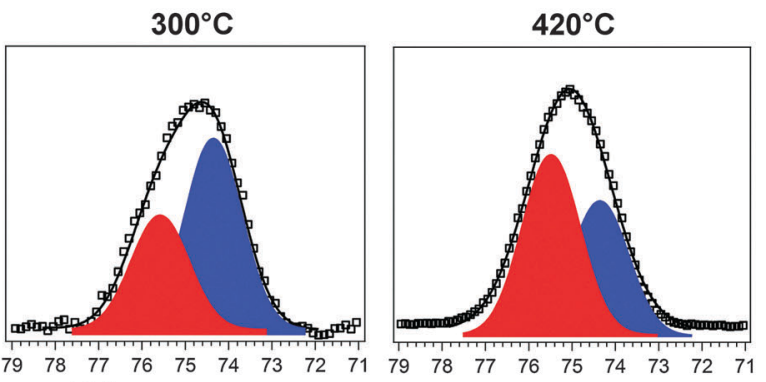

Binding Energy (eV)
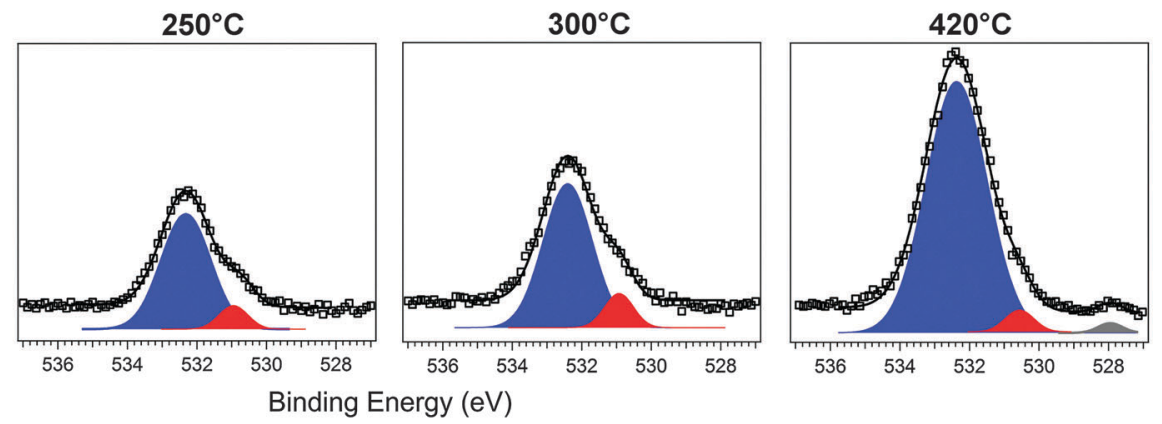

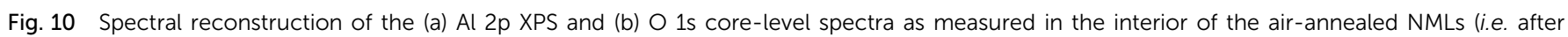
sputtering for $80 \mathrm{~min}$ ). 
(i.e. $\mathrm{O}_{\text {ads }}, \mathrm{O}_{\text {chem }}, \mathrm{O}_{\text {diss }}$ ) cannot be resolved from the measured $\mathrm{Ag}$ 3d peak, because the respective chemical shifts are too small. ${ }^{55,57}$ However, it has been reported that at least $\mathrm{O}_{\text {ads }}$ and $\mathrm{O}_{\text {diss }}$ species can be resolved from the $\mathrm{O}$ 1s core-level region at $\mathrm{BE} \approx 530.4 \mathrm{eV},{ }^{39,55,58}$ which is close to the $\mathrm{BE}$ of the detected $\mathrm{O} 1 \mathrm{~s}$ component at $\mathrm{BE}=530.8 \mathrm{eV}$ (red peak in Fig. 10b). Noteworthily, the intensity of this weak O 1s component slightly increases with increasing temperature up to $300{ }^{\circ} \mathrm{C}$, but again decreases towards higher temperatures, which complies with the above discussion. Thus, the $\mathrm{O} 1 \mathrm{~s}$ component at $\mathrm{BE}=530.8 \mathrm{eV}$ is attributed to adsorbed oxygen species, which gradually penetrate the NML along internal interfaces and defect channels during heating in air. The weak $\mathrm{O} 1 \mathrm{~s}$ peak at $\mathrm{BE}=528.0 \mathrm{eV}$, which is only observed at the highest annealing temperature of $420{ }^{\circ} \mathrm{C}$, is attributed to the formation of chemisorbed $\mathrm{O}_{\text {chem }}$ species at the NML surface and at internal interfaces. ${ }^{39,56}$

Notably the $\mathrm{O} 1 \mathrm{~s}$ and $\mathrm{Al} 2 \mathrm{p}$ chemical species found in the inner part of the $\mathrm{Ag} / \mathrm{AlN}$ sample are preserved throughout the entire NML structure (i.e. up to the sapphire substrate; not shown). This suggests that, even at relatively low temperatures (i.e. $200{ }^{\circ} \mathrm{C}$ ) $\mathrm{O}_{\text {ads }}$ species are able to penetrate the entire NML through defect channels and along internal interfaces.

Summarizing, the XPS chemical state analysis of Ag/AlN NMLs after air annealing up to $420{ }^{\circ} \mathrm{C}$ indicates that the inward diffusion of oxygen species along defect channels inside the NML becomes thermally activated at temperatures as low as $200{ }^{\circ} \mathrm{C}$. The inwardly diffusing $\mathrm{O}$ atoms preferentially react with the AlN barriers to form amorphous $\mathrm{Al}_{2} \mathrm{O}_{3}$, but also chemically interact with the confined $\mathrm{Ag}$ layers. The adsorption and dilution of (electronegative) atomic impurities (i.e. $\mathrm{O}, \mathrm{Cl}$ ) are known to affect vacancy formation energy in $\mathrm{Ag}^{59-61}$ enhancing its surface self-diffusion ${ }^{62,63}$ to an extent which is not found under vacuum. ${ }^{64}$ Recent DFT calculations indicate that the $\mathrm{Ag}$ vacancy formation energy can be reduced by an order of 3 if oxygen is adsorbed or diluted in Ag. ${ }^{60}$ Evidently, this effect should be very pronounced for $\mathrm{Ag}$ nanolayers with thicknesses of only $5 \mathrm{~nm}$, since a majority of $\mathrm{Ag}$ atoms will be associated with the interfaces between the (partially oxidized) AlN barrier layers and the confined $\mathrm{Ag}$ nanolayers. It is therefore proposed that the enhanced mobility of $\mathrm{Ag}$ upon annealing in ambient atmospheres (as compared to annealing in vacuum) originates from the reduction of the activation energies for vacancy formation in the confined $\mathrm{Ag}$ nanolayers (as induced by the interaction with adsorbed $\mathrm{O}$ ), which enhances their atomic mobility. Therefore, an O-rich atmosphere during the thermal processing of the $\mathrm{Ag} / \mathrm{AlN}$ NML brazing fillers is of key importance in promoting extensive Ag migration for low-temperature joining.

\section{Conclusions}

This work presents a comprehensive investigation of the microstructural evolution of $(\mathrm{Ag} / \mathrm{AlN})_{5 \mathrm{~nm} / 10 \mathrm{~nm}} \mathrm{NML}$ coatings on $\alpha-\mathrm{Al}_{2} \mathrm{O}_{3}(1 \overline{1} 02)$ substrates upon heating under vacuum or in air by electron microscopy (SEM and TEM), X-ray spectroscopy (XPS) and diffraction (in situ and ex situ XRD).
Fast annealing in air up to $420{ }^{\circ} \mathrm{C}$ induces extensive migration of $\mathrm{Ag}$ from the interior of the NML to the surface at temperatures as low as $200{ }^{\circ} \mathrm{C}$, which results in the formation of a high density of spherical $\mathrm{Ag}$ particles at the NML surface. In the temperature range of $200{ }^{\circ} \mathrm{C}<T<280{ }^{\circ} \mathrm{C}$, large compressive stresses are accumulated in the confined Ag layers (due to the thermal expansion mismatch with the substrate). However, these stresses become fully relaxed upon further heating in the range $280{ }^{\circ} \mathrm{C}<$ $T<400{ }^{\circ} \mathrm{C}$, in accordance with the observed migration of the confined Ag to the NML surface. The Ag particles on the surface can coarsen at a much higher rate as compared to the (still) confined Ag nano-grains and also exhibit a nearly stress-free state during further heating and subsequent cooling.

Strikingly, the outward migration of $\mathrm{Ag}$ is much less pronounced for an identical heat treatment under vacuum, as well as for much thicker sandwiched Ag films. As evidenced by the XPS analysis of the annealed $\mathrm{Ag} / \mathrm{AlN} \mathrm{NML}$, oxygen penetrates the pristine $\mathrm{Ag} / \mathrm{AlN}$ NML along grain boundaries, internal interfaces and growth defects at temperatures as low as $250{ }^{\circ} \mathrm{C}$. This inwardly diffusing $\mathrm{O}$ preferentially reacts with the AlN barrier layers to form an amorphous $\mathrm{Al}_{2} \mathrm{O}_{3}$ phase, but concurrently also interacts with the confined $\mathrm{Ag}$ nanolayers. The chemical interaction between inwardly diffusing $\mathrm{O}$ and $\mathrm{Ag}$ reduces the activation energy for vacancy formation in the $\mathrm{Ag}$ nanolayers and thereby enhances the mobility of $\mathrm{Ag}$ atoms at low temperatures.

It is concluded that the reduction of the sum of grain-boundary and interface energies provides the main driving force for $\mathrm{Ag}$ outward migration and grain coarsening up to $420{ }^{\circ} \mathrm{C}$; compressive stress relaxation provides an additional driving force contribution over a limited $T$-range of $280{ }^{\circ} \mathrm{C}<T<400{ }^{\circ} \mathrm{C}$. Evidently, an O-rich atmosphere during thermal processing is of key importance to enhance the kinetics of the Ag migration process at low temperatures, which could be exploited for novel low-temperature joining applications.

\section{Acknowledgements}

We acknowledge the Paul Scherrer Institut, Villigen, Switzerland for the provision of synchrotron radiation beamtime at beamline X03MA of the SLS and would like to thank M. Lange, N. Casati and A. Cervellino for assistance. A part of this work was carried out within a project No UMO-2015/17/B/ST8/01434 financed by the National Science Centre, Poland. The authors are grateful to D. Ariosa for his support with the XRD analysis. The authors acknowledge the financial support of EU FP7-PEOPLE-2013IRSES Project EXMONAN - Experimental investigation and modelling of nanoscale solid state reactions with high technological impact.

\section{References}

1 N. Nerngchamnong, L. Yuan, D.-C. Qi, J. Li, D. Thompson and C. A. Nijhuis, Nat. Nanotechnol., 2013, 8, 113-118.

2 R. S. Devan, R. A. Patil, J.-H. Lin and Y.-R. Ma, Adv. Funct. Mater., 2012, 22, 3326-3370. 
3 P. Zrazhevskiy, M. Sena and X. Gao, Chem. Soc. Rev., 2010, 39, 4326.

4 Y. Sun, S. Gao and Y. Xie, Chem. Soc. Rev., 2014, 43, 530-546.

5 R. Ghosh Chaudhuri and S. Paria, Chem. Rev., 2012, 112, 2373-2433.

6 M. Chiodi, C. P. Cheney, P. Vilmercati, E. Cavaliere, N. Mannella, H. H. Weitering and L. Gavioli, J. Phys. Chem. C, 2012, 116, 311-318.

7 W. Y. Teoh, R. Amal and L. Mädler, Nanoscale, 2010, 2, 1324.

8 C. Suryanarayana and N. Al-Aqeeli, Prog. Mater. Sci., 2013, 58, 383-502.

9 M. Batzill, Surf. Sci. Rep., 2012, 67, 83-115.

10 D. M. Mattox, Handbook of Physical Vapor Deposition (PVD) Processing, Elsevier Ltd, Oxford, 2nd edn, 2010.

11 Nanostructured Materials and Their Applications, ed. S. Logothetidis, Springer Berlin Heidelberg, Berlin, Heidelberg, 2012.

12 Y. P. Li and G. P. Zhang, Acta Mater., 2010, 58, 3877-3887.

13 H. Mizuno, S. Mossa and J.-L. Barrat, Sci. Rep., 2015, 5, 14116.

14 B. H. Cheng, H. W. Chen, K. J. Chang, Y.-C. Lan and D. P. Tsai, Sci. Rep., 2015, 5, 18172.

15 A. Allain, J. Kang, K. Banerjee and A. Kis, Nat. Mater., 2015, 14, 1195-1205.

16 G. Fernando, Metallic Multilayers and their Applications: Theory, Experiments, and Applications related to Thin Metallic Multilayers, Elsevier, 2011.

17 C. Bazioti, G. P. Dimitrakopulos, T. Kehagias, P. Komninou, A. Siozios, E. Lidorikis, D. C. Koutsogeorgis and P. Patsalas, J. Mater. Sci., 2014, 49, 3996-4006.

18 A. Siozios, D. C. Koutsogeorgis, E. Lidorikis, G. P. Dimitrakopulos, T. Kehagias, H. Zoubos, P. Komninou, W. M. Cranton, C. Kosmidis and P. Patsalas, Nano Lett., 2012, 12, 259-263.

19 G. Pigozzi, A. Antušek, J. Janczak-Rusch, M. Parlinska-Wojtan, D. Passerone, C. Antonio Pignedoli, V. Bissig, J. Patscheider and L. P. H. Jeurgens, Appl. Phys. Lett., 2012, 101, 181602.

20 J. Janczak-Rusch, M. Chiodi, C. Cancellieri, F. Moszner, R. Hauert, G. Pigozzi and L. P. H. Jeurgens, Phys. Chem. Chem. Phys., 2015, 17, 28228-28238.

21 P. Peng, A. Hu, A. P. Gerlich, G. Zou, L. Liu and Y. N. Zhou, ACS Appl. Mater. Interfaces, 2015, 7, 12597-12618.

22 L. Frey, P. Parrein, L. Virot, C. Pellé and J. Raby, Appl. Opt., 2014, 53, 1663.

23 A. Siozios, N. Kalfagiannis, D. V. Bellas, C. Bazioti, G. P. Dimitrakopulos, G. Vourlias, W. M. Cranton, E. Lidorikis, D. C. Koutsogeorgis and P. Patsalas, Nanotechnology, 2015, 26, 155301.

24 A. Siozios, H. Zoubos, N. Pliatsikas, D. C. Koutsogeorgis, G. Vourlias, E. Pavlidou, W. Cranton and P. Patsalas, Surf. Coat. Technol., 2014, 255, 28-36.

25 A. Siozios, D. C. Koutsogeorgis, E. Lidorikis, G. P. Dimitrakopulos, N. Pliatsikas, G. Vourlias, T. Kehagias, P. Komninou, W. Cranton, C. Kosmidis and P. Patsalas, J. Phys. D: Appl. Phys., 2015, 48, 285306.

26 G. Kaptay, J. Janczak-Rusch, G. Pigozzi and L. P. H. Jeurgens, J. Mater. Eng. Perform., 2014, 23, 1600-1607.
27 G. Kaptay, J. Janczak-Rusch and L. P. H. Jeurgens, J. Mater. Eng. Perform., 2016, in review.

28 A. Bergamaschi, A. Cervellino, R. Dinapoli, F. Gozzo, B. Henrich, I. Johnson, P. Kraft, A. Mozzanica, B. Schmitt and X. Shi, J. Synchrotron Radiat., 2010, 17, 653-668.

29 P. R. Willmott, D. Meister, S. J. Leake, M. Lange, A. Bergamaschi, M. Bge, M. Calvi, C. Cancellieri, N. Casati, A. Cervellino, Q. Chen, C. David, U. Flechsig, F. Gozzo, B. Henrich, S. Jäggi-Spielmann, B. Jakob, I. Kalichava, P. Karvinen, J. Krempasky, A. Lüdeke, R. Lüscher, S. Maag, C. Quitmann, M. L. Reinle-Schmitt, T. Schmidt, B. Schmitt, A. Streun, I. Vartiainen, M. Vitins, X. Wang and R. Wullschleger, J. Synchrotron Radiat., 2013, 20, 667-682.

30 F. Bechstedt, Principles of surface physics, Springer, Berlin, 2003.

31 F. Moszner, C. Cancellieri, M. Chiodi, S. Yoon, D. Ariosa, J. Janczak-Rusch and L. P. H. Jeurgens, Acta Mater., 2016, 107, 345-353.

32 R. S. Telyatnik, A. V. Osipov and S. A. Kukushkin, Phys. Solid State, 2015, 57, 162-172.

33 P. Bindu and S. Thomas, J. Theor. Appl. Phys., 2014, 8, 123-134.

34 Y. S. Touloukian, R. K. Kirby, R. E. Taylor and P. D. Desai, Thermal Expansion: Metallic Elements and Alloys, Thermophysical Properties of Matter, IFI/Plenum, New York, vol. 12, 1975, ISBN 0-306-67032-1.

35 W. M. Yim and R. J. Paff, J. Appl. Phys., 1974, 45, 1456.

36 D. Flötotto, Z. M. Wang, L. P. H. Jeurgens and E. J. Mittemeijer, Appl. Phys. Lett., 2014, 104, 091901.

37 B. Lehmert, J. Janczak-Rusch, G. Pigozzi, P. Zuraw, F. La Mattina, L. Wojarski, W. Tillmann and L. P. H. Jeurgens, Mater. Trans., JIM, 2015, 56, 1015-1018.

38 J. B. Malherbe, Crit. Rev. Solid State Mater. Sci., 1994, 19, 55-127.

39 X. Bao, M. Muhler, T. Schedel-Niedrig and R. Schlögl, Phys. Rev. B: Condens. Matter Mater. Phys., 1996, 54, 2249.

40 G. I. N. Waterhouse, G. A. Bowmaker and J. B. Metson, Surf. Interface Anal., 2002, 33, 401-409.

41 F. Jose, R. Ramaseshan, S. Dash, S. Bera, A. K. Tyagi and B. Raj, J. Phys. D: Appl. Phys., 2010, 43, 075304.

42 Y. Geng and M. G. Norton, J. Mater. Res., 1999, 14, 2708-2711.

43 M. Sternitzke, J. Am. Ceram. Soc., 1993, 76, 2289-2294.

44 M. Sterntzke and G. Müller, J. Am. Ceram. Soc., 1994, 77, 737-742.

45 M. MacKenzie and A. J. Craven, J. Phys. D: Appl. Phys., 2000, 33, 1647.

46 L. Li, J. C. Yang and T. K. Minton, J. Phys. Chem. C, 2007, 111, 6763-6771.

47 J. Meng, X. Liu, Z. Fu, X. Wang and L. Hao, Appl. Surf. Sci., 2015, 347, 109-115.

48 C.-Y. Lin and F.-H. Lu, J. Eur. Ceram. Soc., 2008, 28, 691-698. 49 P. W. Wang, J.-C. Hsu, Y.-H. Lin and H.-L. Chen, Surf. Interface Anal., 2011, 43, 1089-1094.

50 L. P. H. Jeurgens, W. G. Sloof, F. D. Tichelaar and E. J. Mittemeijer, Surf. Sci., 2002, 506, 313-332. 
51 F. Reichel, L. P. H. Jeurgens, G. Richter and E. J. Mittemeijer, J. Appl. Phys., 2008, 103, 093515.

52 G. V. Soares, K. P. Bastos, R. P. Pezzi, L. Miotti, C. Driemeier, I. J. R. Baumvol, C. Hinkle and G. Lucovsky, Appl. Phys. Lett., 2004, 84, 4992-4994.

53 W. K. Choi, S. C. Choi, H.-J. Jung and S. K. Koh, Nucl. Instrum. Methods Phys. Res., Sect. B, 1999, 148, 740-744.

54 T. C. R. Rocha, A. Oestereich, D. V. Demidov, M. Hävecker, S. Zafeiratos, G. Weinberg, V. I. Bukhtiyarov, A. KnopGericke and R. Schlögl, Phys. Chem. Chem. Phys., 2012, 14, 4554 .

55 D. E. Starr, Z. Liu, M. Hävecker, A. Knop-Gericke and H. Bluhm, Chem. Soc. Rev., 2013, 42, 5833.

56 A. J. Nagy, G. Mestl, D. Herein, G. Weinberg, E. Kitzelmann and R. Schlögl, J. Catal., 1999, 182, 417-429.
57 V. Bukhtiyarov, A. Nizovskii, H. Bluhm, M. Havecker, E. Kleimenov, A. Knopgericke and R. Schlogl, J. Catal., 2006, 238, 260-269.

58 D. Y. Zemlyanov, A. Nagy and R. Schlögl, Appl. Surf. Sci., 1998, 133, 171-183.

59 R. Kirchheim, Acta Mater., 2007, 55, 5139-5148.

60 T. E. Jones, T. C. R. Rocha, A. Knop-Gericke, C. Stampfl, R. Schlögl and S. Piccinin, Phys. Chem. Chem. Phys., 2014, 16, 9002.

61 T. E. Jones, T. C. R. Rocha, A. Knop-Gericke, C. Stampfl, R. Schlögl and S. Piccinin, Phys. Chem. Chem. Phys., 2015, 17, 9288-9312.

62 G. E. Rhead, Acta Metall., 1965, 13, 223-226.

63 W. M. Sears and D. A. Love, J. Appl. Phys., 1995, 77, 2407.

64 W.-X. Li, C. Stampfl and M. Scheffler, Phys. Rev. B: Condens. Matter Mater. Phys., 2002, 65, 075407. 